\title{
Multiscale ANAlysis OF MASCUlinity - AN EXPLORATORY STUDY
}

\author{
Luca Kozma \& Ferenc Kocsor \\ Institute of Psychology, University of Pécs, Hungary
}

kozma.luca@gmail.com

\begin{abstract}
In the present study we investigated the connection between male dominance and masculinity. We used questionnaires to discover how self-rated dominance, identification with masculinity ideologies, aggression, and attitudes towards women, are related. Our analyses revealed that the two different gender role questionnaires we used (Bem's Sex Role Inventory, Multicultural Masculine Ideology Scale) may focus on different aspects of masculinity, which was also reflected in their different relations to other variables - aggression, dominance, and sexism. We briefly review the main concepts related to gender roles, and discuss the results of the analyses within the frames of Social Role Theory.
\end{abstract}

Keywords: Gender role, aggression, dominance, masculinity.

\section{INTRODUCTION}

One theoretical framework we can use when explaining gender differences is Social Role Theory. This explains differences in behavior as the consequence of gender roles: masculinity and femininity. In this sense, this theory suggests that the significant differences which exist between the sexes in many behavioral traits are mostly social rather than inherently biological. For instance, boys learn that aggression is an acceptable behavior as it fits the masculine role. Meanwhile girls learn that aggression is not what is expected of them. The mere fact that there are significant differences between the sexes in aggression (see Bettencourt \& Miller, 1996; Archer, 2004), however, might be used to support both social and biological explanations. Of course, social context might also influence the expression of even those behaviors which have biological factors - such as hormones - that contribute to sex differences. Just like many other personality traits, gender role identification shows a great variability between individuals. In the case of 
aggression, several studies support this, and report that gender role identification is a better predictor of aggression than biological sex itself (Richardson \& Hammock, 2007). The view about how the expectations of society may lead to a divergence in the behavior of the two sexes, changed several times since the middle of the last century. In the '50s, Parsons in his Social Role Theory explained sex roles as the consequence of differences in the roles men and women have in the family: "instrumental" and "expressive", respectively. This way, the focus was on the function of gender, which was thought by many to correspond to innate sex differences (Parsons \& Bales, 1956). It was also suggested later that the idea that masculinity is the product of social norms allows for change in the society: when the agencies of socialization - family, school, media present new expectations, change will happen (Connell, 2005).

This change came about in the '70s when men's studies (also known as men and masculinities) were influenced by feminism. In this era the traditional female sex role was starting to become considered oppressive. At the same time, with human rights broadening, it became clear that there is a hierarchy of power among men as well and not all men are equal - black men and homosexual men were considered subordinate. This diversity led to Connell's differentiation of masculinities and the birth of "hegemonic masculinity" (Connell, 2005). Moreover, Connell theorizes, masculinities are not only differentiated, they are also against one another. When one masculinity dominates others, a hegemony of masculinity is created. Men who possess that hegemony are in a superior position. This way, different masculinities can exist at the same time, which are the results of different individual life histories - and one of them is more dominant than the others (Haywood \& Ghaill, 2003).

As we have seen, apart from biological factors, sex differences in behavior can emerge on the basis of the variation in two social factors: gender role identification, which shows individual differences, and gender role norms, which may change along with the changes in the society. Gender role norms are rules that tell us what is expected of a man or a woman; that is, how he/she should behave. Some theorists say that these influence even mate preferences. For example, in one study (Johannesen-Schmidt \& Eagly, 2002) researchers found that women who endorsed traditional female roles preferred older men compared with those who did not identify with traditional roles. The same thing was true for men's preferences: the more men expected women to follow traditional roles, the younger the preferred age was for spouses. Though these kinds of decisions primarily influence the individuals' mating success, these are made in a social context. Hence, depending on the strength of prevailing norms within the society and the extent to which these norms correlate with evolutionary constraints, it might be almost irrelevant what kind of long term consequences the particular decision might pose on the individual's reproductive success. In terms of the Social Role Theory, the extent to which people tend to judge others according to their willingness to follow stereotypical gender roles is assessed by their level of sexism. This concept is usually used to explain one's negative bias towards another individual, based on nothing more than their biological sex.

The aforementioned study made by Johannesen-Schmidt and Eagly (JohannesenSchmidt \& Eagly, 2002) also used sexism through which endorsement of gender role norms can be grasped. However, Glick and Fiske's Ambivalent Sexism Inventory (Glick \& Fiske, 1996) proposed that sexism is actually a multidimensional construct. It refers 
not only to hostility towards women, but a subjectively positive feeling - which is referred to as benevolent sexism - as well. It describes an attitude that views women stereotypically in restrictive - oppressed - roles. The relation between gender role norms and sexism was also supported by a study which used behavioral measures to assess endorsement to gender norms (Fox \& Tang, 2014). It was found that male video game players' endorsement of masculine norms predicted their sexist attitudes towards female players. It seems that not only explicit, but also implicit masculine self-concept is associated with sexism - both hostile and benevolent (Wong, Burkley, Bell, Wang, \& Klann, 2017).

When talking about sexism, the question of aggression and violence against women is hard to avoid. Several studies found associations between hostile sexism and intimate partner violence (Mthembu et al., 2014; Renzetti, Lynch, \& DeWall, 2015) whereas benevolent sexism seems to decrease the occurrence of violence in a relationship (e.g. Allen, Swan, \& Raghavan, 2009). Similar to sexism, egalitarian gender beliefs seem to yield mixed results when explaining relationship aggression. Some studies have found that beliefs in power difference (i.e., dominance) within a relationship are good predictors of aggression towards a partner (O'Leary, Smith Slep, \& O'Leary, 2007; Moyano, Monge, \& Sierra, 2017) while others don't support this notion (e.g., Karakurt \& Cumbie, 2012). Furthermore, it appears that dominance is also a predictor of aggression when we talk about same-sex situations, not only within the context of romantic relationships (Archer \& Webb, 2006).

As presented above, gender role identification, aggression, sexism and dominance seem to be related to one another. However, the direction and strength of the relation may vary according to the historical period and the society being studied (Doss \& Hopkins, 1998; Janey, Janey, Goncherova, \& Savchenko, 2005). In the present study we wanted to shed light on this complex relationship, putting masculinity measures in the focus of the analyses. Our primary aim was to collect a preliminary dataset to explore which of the above listed variables are the best predictors of self-perceived masculinity in a contemporary Central-European society.

\section{METHOD}

\section{Participants and Procedure}

Forty-three Hungarian male students of the University of Pécs, Hungary, participated in our study (mean age $=21.28, \mathrm{SD}=2.21$ ). One participant did not respond to all questions on the MMIS questionnaire, so for those analyses which included this variable, the sample size was 42 . The participants did not get any reward or credits for participating, they volunteered out of interest. Before giving their written consent, they were informed what participation would entail and they were ensured that the study had been approved by the Ethics Committee. As part of a bigger project, portrait photos were taken of them that we did not include in the present study. Participants were asked to complete several questionnaires, 5 of which are presented in the current article. All questionnaires were administered in random order, for groups of 3-4 people. The time restraint of photographing and the voluntary nature of our recruiting determined the size of our sample. 


\section{Questionnaires}

Dominance and assertiveness

To measure dominance, we used the 11-item dominance subscale of the IPIP (CPI $[\mathrm{Nar}])$, which captures self-aggrandizing motives. In contrast, the 10-item assertiveness scale (CPI [Do]) focuses more on pro-social drives towards dominance (Goldberg et al., 2006).

Ambivalent Sexism Inventory (ASI; Glick \& Fiske, 1996)

Glick \& Fiske's Ambivalent Sexism Inventory has two subscales - hostile and benevolent - which measure different sides of the same components of attitudes towards women: Paternalism (dominative and protective), Gender Differentiation (competitive and complementary), and Heterosexuality (hostile and intimate). The hostile aspect of sexism can be described by Dominative Paternalism, Competitive Gender Differentiation and Heterosexual Hostility. Its subscale, thus, includes items such as: "Most women fail to appreciate fully all that men do for them." Benevolent sexism is comprised by Protective Paternalism, Complementary Gender Differentiation and Heterosexual Intimacy. Its subscale uses items such as: "Women should be cherished and protected by men." The inventory contains 22 items and it uses a 6-point Likert scale to assess the degree to which participants agree with each item ( $0=$ disagree strongly; $5=$ agree strongly).

Buss-Perry Aggression Questionnaire (BPAQ; Buss \& Perry, 1992):

This questionnaire contains four subscales: Physical Aggression, Verbal Aggression, Anger and Hostility. A five-point scale was used: 1=Does not apply to me, 2=Usually does not apply to me, $3=$ Sometimes applies to me, $4=$ Often applies to me and 5=Very often applies to me.

Bem's Sex-Role Inventory (BSRI; Bem, 1974):

In this inventory the author considered masculinity and femininity to be independent dimensions. Depending on the endorsement of sex roles, one can be described as masculine, feminine or "androgynous" (both masculine and feminine). It contains 60 adjectives and using a seven-point scale, the person indicates how well the personality characteristics describe them ( $1=$ never true; $7=$ always true).

Multicultural Masculinity Ideology Scale (MMIS; Doss \& Hopkins, 1998):

This scale represents the 2nd generation of masculinity measurements - instead of focusing on traditional (hegemonic) masculinity, it recognizes the variety of masculinities different groups have. Depending on what population researchers use it, the factor structure and subscales vary, with some common dimensions - which Doss and Hopkins call etic (Doss \& Hopkins, 1998; Thompson Jr. \& Bennett, 2015). The questionnaire has two parts, one focuses on masculinity ideology while the other corresponds to this by matching a self-report behavior to the ideology (e.g., "Guys should not cry even when something bad happens" and "I do not cry when something bad happens to me or my loved ones."). 


\section{RESULTS}

Pearson's correlation (Table 1) using a 5000 samples bootstrapping at a 95\% confidence level revealed that higher level of masculinity on the Bem Sex-Role Inventory was connected to a high level of assertiveness $(r=0.699 ; \mathrm{p}<0.001)$ and dominance $(r=0.497$; $\mathrm{p}=0.001$ ), as well as to verbal aggression (Buss-Perry Aggression Questionnaire; $\mathrm{r}=$ $0.302 ; \mathrm{p}=0.049$ ). Scores on the Multicultural Masculinity Ideology Scale had a significant positive correlation to higher scores of benevolent sexism (Ambivalent Sexism Inventory; $\mathrm{r}=0.410 ; \mathrm{p}=0.007$ ).

We used stepwise linear regressions to reveal what explains best the differences we found in the two masculinity measurements. The best predictor of masculinity measured by MMIS was benevolent sexism ( $F=8.106 ; \operatorname{Radj} 2=0.148 ; \beta=0.410 ; p=0.007)$. To calculate the $95 \%$ confidence interval for the unstandardized coefficient, we repeated the analysis with enter method, using 5000 bootstrap samples and benevolent sexism as the only predictor $(\mathrm{CI}=.240-1.019)$. In contrast, there were two models that could predict scores on the masculinity subscale of the BSRI. One was assertiveness ( $F=39.079$; $\operatorname{Radj} 2=0.476, \beta=0.699 ; \mathrm{p}<0.001)$ and the other one was assertiveness and benevolent sexism together $(F=29.662 ; \mathrm{p}<0.001$; Radj2=0.577; $\beta 1=0.758, \mathrm{p}<0.001 ; \beta 2=-0.336$, $\mathrm{p}=0.002)$. Unlike for MMIS, here lower scores of benevolent sexism were good predictors of BSRI. To calculate the confidence intervals, we used the enter method with 5000 bootstrap samples and the predictor variables determined in the stepwise analysis (assertiveness as predictor: $\mathrm{CI} 1=.58-.106$; assertiveness and benevolent sexism as predictors: $\mathrm{CI} 2=-.039--.014)$. Cronbach's alpha values of the questionnaires calculated for this sample are reported in Table 2.

Table 2: Cronbach's alpha values of the subscales used.

\begin{tabular}{cccccccccccc}
\hline MMIS & $\begin{array}{c}\text { MMIS } \\
\text { behavi- } \\
\text { our }\end{array}$ & $\begin{array}{c}\text { BSRI } \\
\text { mascu- } \\
\text { linity }\end{array}$ & $\begin{array}{c}\text { BSRI } \\
\text { femin- } \\
\text { inity }\end{array}$ & $\begin{array}{c}\text { IPIP } \\
\text { assertive- } \\
\text { ness }\end{array}$ & $\begin{array}{c}\text { IPIP } \\
\text { domi- } \\
\text { nance }\end{array}$ & $\begin{array}{c}\text { BPAQ } \\
\text { physical }\end{array}$ & $\begin{array}{c}\text { BPAQ } \\
\text { verbal }\end{array}$ & $\begin{array}{c}\text { BPAQ } \\
\text { anger }\end{array}$ & $\begin{array}{c}\text { BPAQ } \\
\text { hostility }\end{array}$ & $\begin{array}{c}\text { ASI } \\
\text { benevolent }\end{array}$ & $\begin{array}{c}\text { ASI } \\
\text { hostile }\end{array}$ \\
\hline 0.72 & -0.07 & 0.84 & 0.61 & 0.84 & 0.63 & 0.73 & 0.46 & 0.80 & 0.72 & 0.64 & 0.73 \\
\hline
\end{tabular}

\section{DISCUSSION}

In our study we used two different masculinity measurements to see the effect of gender role identification on aggression, dominance and sexism. One of those measurements was Bem's Sex-Role Inventory. In the '70s, when it was constructed, it was considered innovative - it hypothesized that masculinity and femininity are not the two ends of the same spectrum but two separate yet relating dimensions - this way a person can be both masculine and feminine. In these terms, being masculine means that the person with high scores on that subscale internalized characteristics that society deems masculine (Bem, 1974). This, though, could be seen as what Connell referred to as hegemonic masculinity - one masculinity being dominant over another (Connell, 1987), which, in this day and age, encompasses our views on what the male sex role means. The 
Table 1: Pearson correlations of the two masculinity questionnaires with other constructs.

\begin{tabular}{|c|c|c|c|c|c|c|c|c|c|c|c|c|c|}
\hline & & MMIS & $\begin{array}{c}\text { MMIS } \\
\text { behaviorr }\end{array}$ & $\begin{array}{c}\text { BSRI } \\
\text { masculinit }\end{array}$ & $\begin{array}{c}\text { BSRI } \\
\text { femininity }\end{array}$ & $\begin{array}{c}\text { IPIP } \\
\text { assertivene }\end{array}$ & $\begin{array}{c}\text { IPIP } \\
\text { dominance }\end{array}$ & $\begin{array}{c}\text { BPAQ } \\
\text { physical }\end{array}$ & $\begin{array}{l}\text { BPAQ } \\
\text { verbal }\end{array}$ & $\begin{array}{l}\text { BPAQ } \\
\text { anger }\end{array}$ & $\begin{array}{c}\text { BPAQ } \\
\text { hostility }\end{array}$ & $\begin{array}{c}\text { ASI } \\
\text { benevolent }\end{array}$ & ASI hostile \\
\hline \multirow{5}{*}{ MMIS } & $r$ & 1 & .022 & .007 & -.062 & .030 & .065 & .259 & .054 & .107 & -.010 & $.410^{* *}$ & .074 \\
\hline & $p$ & & .890 & .963 & .696 & .851 & .682 & .097 & .733 & .502 & .949 & .007 & .640 \\
\hline & $C I$ & & $-.228-.293$ & $-.239-.286$ & $-.342-.255$ & $-.252-.341$ & $-.301-.413$ & $-.078-.570$ & $-.263-.365$ & $-.239-.417$ & $-.416-.357$ & $.187-.579$ & $-.244-.375$ \\
\hline & bias & & -.002 & .002 & .005 & .000 & -.006 & .003 & .005 & -.002 & -.021 & -.001 & -.001 \\
\hline & Std Er & & .133 & .132 & .152 & .145 & .184 & .168 & .160 & .166 & .203 & .101 & .158 \\
\hline \multirow{5}{*}{$\begin{array}{c}\text { MMIS } \\
\text { behavior }\end{array}$} & $r$ & .022 & 1 & .250 & .000 & .284 & .069 & -.082 & .153 & .063 & .066 & .008 & -.015 \\
\hline & $p$ & .890 & & .111 & 1.000 & .068 & .666 & .604 & .334 & .693 & .679 & .960 & .926 \\
\hline & $C I$ & $-.228-.293$ & & $-.064-.483$ & $-.334-.340$ & $-.012-.538$ & $-.270-.357$ & $-.377-.213$ & $-.219-.503$ & $-.257-.335$ & $-.210-.341$ & $-.318-.338$ & $-.317-.294$ \\
\hline & bias & -.002 & & -.008 & .001 & -.006 & -.005 & -.001 & .008 & -.003 & .002 & -.005 & .001 \\
\hline & Std Er & .133 & & .132 & .172 & .139 & .159 & .151 & .190 & .151 & .140 & .166 & .154 \\
\hline \multirow{5}{*}{$\begin{array}{c}\text { BSRI } \\
\text { mascu- } \\
\text { linity }\end{array}$} & $r$ & .007 & .250 & 1 & .018 & $.720^{* *}$ & $.510^{* *}$ & .197 & $.330^{*}$ & .037 & -.223 & -.166 & .021 \\
\hline & $p$ & .963 & .111 & & .911 & $<.001$ & .001 & .257 & .033 & .816 & .156 & .293 & .893 \\
\hline & $C I$ & $-.239-.286$ & $-.046-.483$ & & $-.253-.282$ & $.546-.835$ & $.225-.720$ & $-.060-.427$ & $.040-.603$ & $-.271-.361$ & $-.517-.178$ & $-.438-.075$ & $-.322-.348$ \\
\hline & bias & .002 & -.008 & & .007 & -.003 & -.006 & .004 & 004 & 008 & .015 & -.006 & -.004 \\
\hline & Std Er & .132 & .132 & & .136 & .073 & 127 & .125 & .142 & .161 & .176 & .128 & .171 \\
\hline \multirow{5}{*}{$\begin{array}{c}\text { BSRI } \\
\text { femi- } \\
\text { ninity }\end{array}$} & $r$ & -.062 & .000 & .018 & 1 & -.040 & -.142 & -.048 & .120 & -.123 & .231 & .101 & -.161 \\
\hline & $p$ & .696 & 1.000 & .911 & & .800 & .369 & .763 & .449 & .438 & .142 & .525 & .307 \\
\hline & $C I$ & $-.342-.255$ & $-.334-.340$ & $-.253-.282$ & & $-.387-.293$ & $-.414-.137$ & $-.379-.287$ & $-.202-.412$ & $-.477-.204$ & $-.061-.529$ & $-.139-.384$ & $-.428-.118$ \\
\hline & bias & .005 & .001 & .007 & & -.002 & -.001 & -.001 & .000 & -.005 & .001 & .008 & .000 \\
\hline & Std Er & .152 & .172 & .136 & & .173 & .141 & .171 & .160 & .174 & .152 & .133 & .141 \\
\hline
\end{tabular}

* results are significant at a $\mathrm{p}<.05$ significance level

** results are significant at a $\mathrm{p}<.001$ significance level

a Confidence intervals are based on 5000 bootstrap samples, level is set to $95 \%$ 
Multicultural Masculinity Ideology Scale, on the other hand, assumes that gender role norms are influenced by the culture's norms; hence different cultures have different masculinity ideologies (Doss \& Hopkins, 1998).

Considering these theoretical implications, it is not surprising that the two measurements of masculinity had associations with different personality constructs. The masculinity subscale of BSRI was associated to verbal aggression on the Buss-Perry Aggression Questionnaire. Moreover, only BSRI masculinity had associations with dominance and assertiveness, the MMIS had no relation to either. These results suggest that those men who identify more with traditional gender roles might also endorse the elements of what we consider masculine to a greater level - dominant and aggressive behavior.

Indeed, these two are associated as well. In our study higher points on the verbal aggression and anger subscales of the Buss-Perry Aggression Questionnaire predicted higher dominance points, which has also been proposed by Archer and Webb (Archer \& Webb, 2006). In contrast to their results, the current study found no correlation between dominance and physical aggression.

We used linear regression analyses to find out more about masculinity. These revealed that the two measurements tap into different aspects of masculinity. Benevolent sexism of the Ambivalent Sexism Inventory seems to be a good predictor of masculinity regardless of the scale used. The level of sexism, though, differentiates the two masculinities. When accounting for masculinity measured by the BSRI, the relationship is negative. When we look at the other scale, the MMIS, the relationship between masculinity and benevolent sexism is positive - higher level of sexism predicts greater endorsement of masculine ideologies. Of course, the prediction does not show us the direction of causality.

This difference might be explained by the differences in these questionnaires. In BSRI, masculinity is associated with aggressiveness, independence, assertiveness, competitiveness, and "getting the job done" (Ahmed, Vafaei, Belanger, Phillips, \& Zunzunegui, 2016). On the other hand, the MMIS discusses questions about what "men should" be like when interacting with people - especially with women. Thus it creates the image of a "gallant knight", a strong protector of women and provider of the family. This difference shows perfectly that there isn't one masculinity - culture and traditions create differences in what we consider masculine. It can be grasped through questionnaires that focus on different aspects of men's gender role.

Several limitations of the present study should be also noted. Checking the reliability of the scales we used, it has to be said that most alpha coefficients were above 0.6. One that did not meet this criterion was the verbal aggression subscale of the Buss-Perry Aggression Questionnaire which was lower than in the original Hungarian validation study (Gerevich, Bácskai, \& Czobor, 2007) or Buss and Perry's original study (Buss \& Perry, 1992) (0.46 vs. 0.68 and 0.72 ). This might be due to the nature of our data which was limited in number and was rather homogenous, as it included 43 male university students.

Moreover, our study did not show any correlation between masculinity ideology and self-report behavior on the Multicultural Masculinity Ideology Scale, in contrast to its original description by Doss and Hopkins (Doss \& Hopkins, 1998). This result is somewhat puzzling as the demographics of the participants in the two studies were very 
similar. It must be mentioned, however, that the reliability coefficient of the behavior subscale was negative, which, again, is perplexing, as it contains similar items as the ideology subscale but uses first person singular instead of the general "men should" structure. It is very likely that the fact that subjects had to give responses on a Likert-scale (from complete agreement to complete disagreement) to questions consisting of two or sometimes more subordinate clauses caused confusion, which could be the main reason for the low reliability values. We are currently collecting more data using this scale which might help us clarify what the cause of these discrepancies was.

Finally, most papers regarding gender differences emphasize two theoretical frameworks: Social Role Theory - mentioned in this paper - and Sexual Selection Theory. Even though only one has been the subject of this study, we believe that in future research the aforementioned evolutionary theory might also contribute to the explanation of this social phenomenon.

\section{REFERENCES}

Ahmed, T., Vafaei, A., Belanger, E., Phillips, S. P., \& Zunzunegui, M.-V. (2016). Bem Sex Role Inventory Validation in the International Mobility in Aging Study. Canadian Journal on Aging / La Revue Canadienne Du Vieillissement, 35(3), 348-360. DOI

Allen, C. T., Swan, S. C., \& Raghavan, C. (2009). Gender Symmetry, Sexism, and Intimate Partner Violence. Journal of Interpersonal Violence, 24(11), 1816-1834. DOI

Archer, J. (2004). Sex Differences in Aggression in Real-World Settings: A Meta-Analytic Review. Review of General Psychology, 8(4), 291-322. DOI

Archer, J., \& Webb, I. A. (2006). The relation between scores on the Buss-Perry Aggression Questionnaire and aggressive acts, impulsiveness, competitiveness, dominance, and sexual jealousy. Aggressive Behavior, 32(5), 464-473. DOI

Bem, S. L. (1974). The measurement of psychological androgyny. Journal of Consulting and Clinical Psychology, 42(2), 155-162. DOI

Bettencourt, B. A., \& Miller, N. (1996). Gender differences in aggression as a function of provocation: a meta-analysis. Psychological Bulletin, 119(3), 422-447. DOI

Buss, A. H., \& Perry, M. (1992). The Aggression Questionnaire. Journal of Personality and Social Psychology, 63(3), 452-459. DOI

Buss, D. M., \& Shackelford, T. K. (1997). Human aggression in evolutionary psychological perspective. Clinical Psychology Review, 17(6), 605-619. DOI

Connell, R. W. (1987). Gender and power: society, the person, and sexual politics. Cambridge, UK: Polity Press.

Connell, R. W. (2005). Masculinities. Berkeley, US: University of California Press.

Doss, B. D., \& Hopkins, J. R. (1998). The Multicultural Masculinity Ideology Scale: Validation from Three Cultural Perspectives. Sex Roles, 38(9-10), 719-741. DOI

Eagly, A. H., \& Wood, W. (1999). The origins of sex differences in human behavior: Evolved dispositions versus social roles. American Psychologist, 54(6), 408-423. DOI 
Fox, J., \& Tang, W. Y. (2014). Sexism in online video games: The role of conformity to masculine norms and social dominance orientation. Computers in Human Behavior, 33, 314-320. $\underline{\mathrm{DOI}}$

Gerevich, J., Bácskai, E., \& Czobor, P. (2007). The generalizability of the Buss-Perry Aggression Questionnaire. International Journal of Methods in Psychiatric Research, 16(3), 124-136. $\underline{\text { DOI }}$

Glick, P., \& Fiske, S. T. (1996). The Ambivalent Sexism Inventory: Differentiating hostile and benevolent sexism. Journal of Personality and Social Psychology, 70(3), 491-512. DOI

Goldberg, L. R., Johnson, J. A., Eber, H. W., Hogan, R., Ashton, M. C., Cloninger, C. R., \& Gough, H. G. (2006). The international personality item pool and the future of publicdomain personality measures. Journal of Research in Personality, 40(1), 84-96. DOI

Haywood, C., \& Ghaill, M. M. an. (2003). Men and Masculinities. Milton Keynes, UK: Open University Press.

Johannesen-Schmidt, M. C., \& Eagly, A. H. (2002). Another Look at Sex Differences in Preferred Mate Characteristics: The Effects of Endorsing the Traditional Female Gender Role. Psychology of Women Quarterly, 26(4), 322-328. DOI

Karakurt, G., \& Cumbie, T. (2012). The relationship between egalitarianism, dominance, and violence in intimate relationships. Journal of Family Violence, 27(2), 115-122. DOI

Moyano, N., Monge, F. S., \& Sierra, J. C. (2017). Predictors of sexual aggression in adolescents: Gender dominance vs. rape supportive attitudes. The European Journal of Psychology Applied to Legal Context, 9(1), 25-31. DOI

Mthembu, J., Simbayi, L., Onoya, D., Jooste, S., Mehlomakulu, V., Mwaba, K., ... Kalichman, S. (2014). Sexism, Intimate Partner Violence and Risk Behavior Amongst Men in a South African Township. Violence and Gender, 1(2), 53-59. DOI

O’Leary, K. D., Smith Slep, A. M., \& O'Leary, S. G. (2007). Multivariate models of men's and women's partner aggression. Journal of Consulting and Clinical Psychology, 75(5), 752-764. $\underline{\text { DOI }}$

Parsons, T., \& Bales, R. F. (1956). Family Socialization and Interaction Process. Psychology Press.

Renzetti, C. M., Lynch, K. R., \& DeWall, C. N. (2015). Ambivalent Sexism, Alcohol Use, and Intimate Partner Violence Perpetration. Journal of Interpersonal Violence. DOI

Richardson, D. S., \& Hammock, G. S. (2007). Social context of human aggression: Are we paying too much attention to gender? Aggression and Violent Behavior, 12(4), 417-426. DOI

Thompson Jr., E. H., \& Bennett, K. M. (2015). Measurement of masculinity ideologies: A (critical) review. Psychology of Men \& Masculinity, 16(2), 115-133. DOI

Wong, Y. J., Burkley, M., Bell, A. C., Wang, S.-Y., \& Klann, E. M. (2017). Manly to the core: Measuring men's implicit masculine self-concept via the Semantic Misattribution Procedure. Personality and Individual Differences, 104, 320-325. DOI 